\title{
Cooperation Mode of Higher Vocational Medical Facial Make- up based on Job Demand Analysis Theory
}

\author{
Wei Zhou ${ }^{a}$, Siqing Song ${ }^{b}$ \\ Yichun Vocational Technology College, Yichun 336000, China \\ a zhouzhou9312@163.com, b273121785@qq.com
}

\begin{abstract}
Training center can carry out beauty, body building, make-up and other contents, and the demand for professional talents dispatched by enterprises is gradually increasing. Therefore, it is imperative to strengthen the training of professional talents. Most of the professional training modes in schools adopt theoretical teaching, while the teachers in schools are responsible for the theoretical content and curriculum arrangement of students, which gives full play to the knowledge learning in higher vocational colleges, but neglects the training of students' professional skills, and the trained talents do not have the functions of social skills training and social service, which embodies the purpose of School-enterprise cooperation. Therefore, this paper analyzes the necessity and advantages of School-enterprise cooperation for medical beauty technology specialty, and puts forward several corresponding cooperation modes and teaching practice strategies. personnel training.
\end{abstract}

Keywords: Medical Beauty; Beauty and Skill; School-enterprise Cooperation; Personnel Training.

\section{Introduction}

At present, the demand for talents in the medical beauty technology industry is increasing, which provides good opportunities for the employment of students in the industry. However, some service organizations have lower requirements on the threshold of personnel engaged in medical beauty work, which leads to uneven recognition of medical beauty. How to further accelerate the training of medical beauty technology professionals is extremely urgent. Medical technology is changing with each passing day. Through "School-enterprise cooperation", "work-study combination" and other forms, the curriculum and teaching contents are adjusted in time, and the new knowledge, new technology, new process and new methods in the professional field are highlighted, so as to overcome the disadvantages of outdated contents, slow update, one-sided emphasis on the integrity of the discipline system and inability to meet the needs of professional development [1] [2].

China's huge and potential beauty market, the urgent demand for high-quality technical medical beauty technology professionals, make medical beauty technology professionals and beauty enterprises have a good cooperation foundation and a large cooperation space. School-enterprise cooperation is an important way to improve the quality of school teaching and an inevitable trend of the development of modern vocational education. Higher vocational colleges all over the country are actively exploring the talent training mode of School-enterprise cooperation. Medical beauty technology specialty is special, especially the students' practical ability of School-enterprise cooperation teaching in medical beauty technology specialty is high, but the rigid teaching method and the state of education outline melt into enterprise culture in School-enterprise cooperation [3].In the School-enterprise cooperation, the school has to repeat and lag behind, which leads to the deviation of students' learning style, which makes students generally strengthen their awareness of corporate culture, keeps students' work enthusiasm, and at the same time can overcome the lack of practical ability. Therefore, strengthening the innovation of the new professional education model has become the way to carry out lectures and activities, so that students can feel the power of corporate culture in advance, add some points, adopt educational methods that attach importance to skills and academic qualifications, and emphasize the importance of corporate culture for students' practical ability [4]. Furthermore, it is necessary to cultivate enterprise culture and school education, and at the same time improve students' comprehensive ability. 


\section{The Necessity and Advantages of School-enterprise Cooperation}

\subsection{Medical Beauty Technology Professional School-enterprise Cooperation Model Construction}

The advantage of School-enterprise cooperation lies in that School-enterprise cooperation can give full play to the teaching advantages of schools, and set up corresponding teaching contents to meet the needs of society and market, to enhance the comprehensive quality of medical beauty technology professionals. At the same time, School-enterprise cooperation can smooth the information channels between schools and enterprises, and schools can adjust the personnel training technology and improve the pertinence of teaching content by grasping the information feedback from society and enterprises. And pay attention to the market-oriented role, focusing on improving students' practical skills to meet the needs of market development. In addition, School-enterprise cooperation is a "winwin" teaching mode, which truly achieves the sharing of resources and the communication of information. The school uses its advanced equipment to practice medical beauty technology, and enterprises can also put forward relevant suggestions to schools according to their own talent needs, thus realizing the practice of students' schools and enterprises, thus ensuring the optimization of various educational resources in schools, improving the pertinence of professional education and saving education and education. With the improvement of living standards, people's understanding of health is deepening, and employers have put forward higher requirements for nurses. Therefore, the nursing major in our school is timely, constructs the curriculum system which is suitable for the post demand, and forms a unique talent training mode.

Forty-four third-year students of Chinese medicine major class of Grade 2020 in a certain school were selected, and a School-enterprise cooperation class, Hilaia Women's Health Class, was set up as the experimental group. Another 44 students whose grades in the first academic year were not significantly different from those in the experimental group were selected as the control group. See Table 1 for the comparison of employment adaptation period between the two groups of graduates.

Table 1. Comparison of employment adaptation periods of graduates of the two groups

\begin{tabular}{|c|c|c|}
\hline Time (month) & Experimental group $\mathrm{n}=44$. & Control group $\mathrm{n}=44$. \\
\hline Employment adaptation period & $1.67 \pm 0.66$ & $3.14 \pm 0.71$ \\
\hline
\end{tabular}

It can be seen from Table 1 that there is a very significant difference between the two groups $(\mathrm{P}<$ 0.01), which is statistically significant, suggesting that the graduates of the experimental group can better adapt to the post requirements. see Table 2 for the comparison of graduation salaries between the two groups.

Table 2. Comparison of graduation salary between two groups of graduates

\begin{tabular}{|c|c|c|c|}
\hline Time (year) & Experimental group $\mathrm{n}=44$. & Control group $\mathrm{n}=44$. & $\mathrm{P}$ \\
\hline Half a year after graduation & $3036.64 \pm 525.52$ & $2722.45 \pm 332.35$ & 0.01 \\
\hline Graduated for two years. & $4202.53 \pm 1533.82$ & $3651.35 \pm 968.31$ & 0.048 \\
\hline
\end{tabular}

It can be seen from Table 2 that there is a significant difference between the salary groups of the graduates of the two groups after half a year and two years of graduation $(\mathrm{P}<0.05)$, which is statistically significant.

Traditional teaching mode attaches importance to professional education and neglects comprehensive quality. Students' practical ability is poor, and it is necessary to re-integrate the theoretical system when they enter the enterprise after graduation. There is a big gap between studying in school and the needs of the enterprise. The teaching mode of School-enterprise cooperation will strengthen skills on the basis of studying in school, pay attention to comprehensive quality, integrate enterprise elements, and form a teaching material of School-enterprise cooperation, which makes up for the shortcomings of the traditional teaching mode, and is conducive to students' understanding of 
enterprises in advance, contacting enterprises and improving their comprehensive ability. Facing the huge market of women's health care, the School-enterprise cooperation training mode based on the needs of women's health care posts can increase students' employment competitiveness.

\subsection{Medical Beauty Technology Professional School-enterprise Cooperation Teaching Practice}

Incorporating enterprise culture into School-enterprise cooperation. In the School-enterprise cooperation, the school plays a role in strengthening students' awareness of corporate culture and keeping students' enthusiasm for work. At the same time, by means of lectures and activities, students can feel the power of corporate culture in advance and enhance their awareness of the importance of corporate culture. Furthermore, it is necessary to realize the interaction and complementarity between corporate culture and school education, establish a multifunctional teaching mode, and attract outstanding model employees to the school to explain corporate culture and professional ethics, to attract employees into a professional working situation and lay a good foundation for students majoring in medical beauty technology to enter the society [5]. Cooperative schools, as specific organizers, cooperators and operators of teaching internships, should formulate strict work plans, scientific management and cooperation systems and operational measures. Due to the huge nonmedical beauty market in the beauty market, it also has great development potential and talent demand, especially the urgent demand for high-quality technical professionals, which makes beauty institutions at all levels have a strong willingness to cooperate with the school, which can stabilize the source of high-quality employees in beauty institutions and enhance the corporate culture and brand. Establishing long-term strategic partnership with enterprises can find and understand outstanding students at an early stage, reduce the cost and risk of recruitment, shorten the time for employees to integrate into the company, and alleviate the shortage of professional and technical personnel and the long recruitment and training period. School-enterprise cooperation can complement the relevant advantages of schools and enterprises and share resources.

The instructor should assist the instructor of the internship unit to jointly organize and manage the students, master the safety of the students during the internship cooperation, and inspect the internship process of the students. At the same time, internship instructors should pay close attention to students' ideological trends and solve all kinds of problems in the course of internship cooperation in time, which can promote the smooth employment. Furthermore, School-enterprise cooperation has laid a good foundation for students' employment, and achieved a win-win situation among schools, enterprises and students. Schools can select excellent enterprises according to the changes of market situation, reach training agreements with qualified enterprises, establish medical and beauty technology professionals in schools, and gradually deepen the teaching mode, gradually transitioning from the primary mode of School-enterprise cooperation to the deep-level talent development and training mode, and speeding up the development speed in the industry.

\section{Exploration and Research on the Internship Mode of Medical Beauty Technology Specialty}

\subsection{Analysis of the Causes of Problems in School-enterprise Cooperation of Medical Beauty Technology Specialty}

Due to the lack of relevant policies, the enthusiasm of enterprises is not high: according to the situation of internship of cooperative medical students, the state has issued a series of cooperative policies to encourage and support the participation of enterprises and institutions, but most units are not enthusiastic about internship, and the long-term supervision mechanism for internship students is not complete: during internship, students leave the school and are managed by internship enterprises. Units cooperating with students' internship are scattered all over the country. Schools should supervise and assess the internship of cooperative students on the spot, but there are problems in personnel, cooperation time and financial allocation. Moreover, as two types of individuals, 
enterprises and cooperative schools are managed by different institutions, and large-scale cooperation is mostly responsible for each other, and the checks and balances between them are relatively lacking [6]. To sum up, it leads to incomplete long-term supervision mechanism of technical students' internship, which makes it difficult to form effective supervision and ultimately affects students' internship.

To solve the above problems, we must fully understand the cooperation connotation of work-study combination, explore new ways and modes of work-study combination, make full use of the teaching resources of cooperative schools and the technological advantages of enterprises, and combine them organically, so that students can better master knowledge and apply it flexibly, and improve their professional quality and employment advantages through cooperation, which is more in line with the cooperation needs of enterprises.

\subsection{Medical Beauty Technology Students Start Education Management before Internship}

School-enterprise cooperative teaching management involves both schools and enterprises. On the one hand, excellent teaching backbones of cooperative schools participate in teaching, and school teachers take advantage of holidays to practice at the top of enterprises, learn corporate culture, and understand the employment needs, market orientation and cutting-edge cooperative technologies of enterprises. On the other hand, the enterprise sent business backbones to participate in teaching and discussion, and coordinated the whole curriculum and management plan, which promoted the cooperation and exchange between the two sides. In the School-enterprise cooperation training mode of Chinese medicine specialty in our school, enterprises sign cooperation with schools, and make graduation employment choices more mature. Enterprises need to increase their own charm and attract students to stay in the enterprise and continue to develop. However, there will also be a phenomenon that enterprises invest in cooperation in manpower, energy and financial resources, but students choose another way out.

Therefore, although some achievements have been made in School-enterprise cooperation, longterm cooperation planning should be done well. The variability and richness of the market is a great test for the cooperation mode and graduates. We should keep up with the market development, attach importance to the sustainable development of graduates and the cultivation of students' lifelong learning ability, and actively explore a deeper and more lasting training mode of School-enterprise cooperation. It is necessary to establish the admission system for medical beauty technology specialty before post practice: cooperative schools should, according to the needs of the industry, formulate the skill cooperation question bank and skill assessment criteria for medical beauty technology specialty, and guide and standardize the professional skills training [7]. It is helpful to train students' comprehensive professional ability and improve their skill operation level by examining their skills before practice.

\section{Summary}

At present, there are many researches on School-enterprise training of medicine major, but few researches on School-enterprise cooperation of Chinese medicine major. The talent training model based on the demand of women's health posts proves that the employment rate and employment quality of graduates are significantly improved compared with the traditional model. Rich teaching contents and comprehensive quality improvement programs have brought remarkable teaching effects. School-enterprise cooperation should guarantee the enthusiasm of enterprise cooperation, give enterprises more rights to participate in the planning and teaching of medical beauty technology professional training, build a platform for enterprises to publicize corporate culture on campus, let enterprises make rational use of school professional teaching resources and research and development platform, select suitable medical beauty technology professional talents, and cooperate with each other for mutual benefit, so as to jointly promote the development of both schools and enterprises. 
In a word, there is great potential for School-enterprise cooperation in medical beauty technology specialty. With the increasing demand for medical talents in facial make-up, it is imperative to strengthen the cultivation of professional talents. School-enterprise platform can give full play to the educational advantages of schools and enterprises and realize the all-round cultivation of talents. At present, School-enterprise platform in beauty medical technology industry optimizes students' teaching and skills training through order-based mode, interactive mode and establishing professional training centers, thus realizing the tripartite cooperation among schools, enterprises and students.

\section{References}

[1] Zhang hong, Zhu Jianping. research and practice of new mode of internship for higher vocational students under the background of School-enterprise cooperation-taking civil engineering as an example [J]. 2021 (2012-10):85-87.

[2] Fu Xiangdong. Research on the training mode of secretarial professionals in higher vocational colleges based on School-enterprise cooperation\% Research on the training mode of higher vocal secretarial major talents based on school enterprise cooperation [J]. Journal of Jiamusi Institute of Education, 2017, 000 (004): 32.

[3] Yang Ni. Talking about the mode of School-enterprise cooperation in medical beauty technology specialty [J]. Modern Communication, 2015(8):253-253.

[4] Ding Yun, Huang Liting, Peng Honghua. Research on "School-enterprise Cooperation, Work-study Combination" Talent Training Mode of Medical Beauty Technology Specialty [J]. Academy, 2018(32).

[5] Yang Ni. Talking about the mode of School-enterprise cooperation in medical beauty technology specialty [J]. Modern Communication: the second half of the month, 2015.

[6] Chen Meiren, Huang Yuhui, Liu Jifeng, et al. Research on the reform of the "work-study combination" curriculum system of medical beauty technology major in higher vocational colleges [J]. Chinese Journal of Cosmetic Medicine, 2011, 20(s1):391-392.

[7] Nonghongmi. Probe into the post-applicable talent training mode based on School-enterprise cooperation [J]. New Curriculum Research: Late, 2019(6):111-113. 